\title{
Development and characterization of pullulan-polymethacrylate free films as potential material for enteric drug release
}

\author{
Isabela Angeli de Lima*, Suelen Plaza Pomin, Osvaldo Albuquerque Cavalcanti \\ Department of Pharmacology and Therapeutic, Laboratory of Pharmacotechnology, State University of Maringá/UEM, \\ Maringá, PR, Brazil
}

\begin{abstract}
Free films of pullulan-polymethacrylate associations were produced by casting process to develop a novel target-specific material. For characterization, tests of water vapor permeability, swelling index, infrared absorption spectroscopy, thermogravimetric analysis, scanning electron microscopy and mechanical analysis were performed. The polysaccharide concentration directly influenced vapor permeability and swelling, increasing the values of the latter up to five times when added in a proportion of $20 \%$ (per weight). The individual properties of each polymer were maintained, and chemical interactions were not detected. The films were found to be thermally stable and they had unaltered mechanical properties with the addition of the polysaccharide. The microscopic analysis revealed rugosity that was proportional to pullulan and disorganization of the polymer network at $\mathrm{pH} 6.8$. These results suggest that this novel material has potential for enteric drug release because of synergism between $\mathrm{pH}$ and enzyme dependence.
\end{abstract}

Keywords: Films. Polymeric material. Modified release/enteric release/oral delivery/controlled release. Glucans. Eudragit. Physicochemical characterization.

\section{INTRODUCTION}

Despite patients' acceptance and flexibility with regard to the concept of different methods of dosing, oral drug administration has some therapeutic limitations. Consequently, new formulations, such as modified release, have been proposed (Wasnik, Parmar, 2011). Release in distal regions of the gastrointestinal tract (GIT) is beneficial for the treatment of pathologies that affect the large intestine because the drug is released at the site of action, thus increasing the concentration of the drug at these regions, decreasing the ingested dose, and decreasing side effects (Freire et al., 2006; Nadler, Kam, Rubinstein, 2010; Wasnik, Parmar, 2011; Shukla, Tiwari, 2012). Additionally, these target-specific systems are potentially adequate for the release of protein and peptide therapeutics and protection of their activity from hostile physiological conditions related to stomach $\mathrm{pH}$ and digestive enzymes (Freire et al., 2006; Pinto, 2010; Wen, Park, 2010; Wasnik, Parmar, 2011).

*Correspondence: I. A. Lima. Departamento de Farmácia. Laboratório de Nanotecnologia Farmacêutica. Universidade Estadual do Centro-Oeste/UNICENTRO. Rua Simeão Camargo Varela de Sá, 03 - 85040-080 - Guarapuava, PR, Brazil. E-mail: angeli.isabela@gmail.com
The polymethacrylate Eudragit ${ }^{\circledR}$ FS 30 D (EFS) is an aqueous dispersion at $30 \%$, consisting of a copolymer of methylacrylate, methylmethacrylate, and methacrylic acid and possessing carboxylic acid as the functional group (Evonik, 2016). The dissolution of this synthetic polymer occurs via salt formation and water uptake in fluids at $\mathrm{pH}$ $>7.0$, which allows $\mathrm{pH}$-dependent drug release (Dulin, 2010; Evonik, 2016). Therefore, EFS, when used as a coating in reservoir or in matrix systems, passes through the stomach and small intestine intact and is dissolved only when it contacts neutral-to-alkaline $\mathrm{pH}$ in the colonic segment (Ibekwe et al., 2006).

However, these systems do not always accomplish the goal of efficacious drug release at the desired site. Some pathologies cause colon $\mathrm{pH}$ to undergo extreme variations (e.g., in inflammatory illness, such as ulcerative colitis and Crohn's disease) when the $\mathrm{pH}$ can change in the range of 4.7 to 2.3 (Freire et al., 2006; Nadler, Kam, Rubinstein, 2010; Rabito et al., 2012). This reduction is attributable to fermentation processes in the region (Nadler, Kam, Rubinstein, 2010). Moreover, coatings for colonic release that are exclusively sensitive to $\mathrm{pH}$ can present low specificity because they depend on other factors, such as intestinal transit and coating thickness, for drug release. 
Therefore, the drug is at risk of being prematurely released or causing undesired and slow availability in the descending colon (Nadler, Kam, Rubinstein, 2010; Wen, Park, 2010).

One way to overcome these issues of $\mathrm{pH}$-dependent release systems is the association of the physiological mechanisms present in the GIT. One can combine strategies of applying materials destined for $\mathrm{pH}$-related release with materials that are sensitive to microbiota biodegradation. Thus, upon reaching the colon, both strategies can act synergistically, leading to disintegration of the pharmaceutical form and working as a safety device with target-specific capacity (Ibekwe et al., 2008; Mcconnell, Short, Basit, 2008; Villanova, Oréfice, Cunha, 2010; Basit, Mcconnell, 2011).

Pullulan (PU) is a natural polymer that is extracellularly produced by the fungus Aureobasidium pullulans, in starch and sugar cultures; therefore, it is considered an exopolysaccharide (Xiao, Lim, Tong, 2012). It is characterized as a $\alpha$-glucan and has a linear primary structure composed of subunits of maltotriose linked by $\alpha$-1,6-glycosidic linkages (Pradella, 2006; Introzzi et al., 2012). This structure allows PU to have good solubility in water (Xiao, Lim, Tong, 2012).

This exopolysaccharide has no odor, taste, or toxicity. The molecular weight is between 8000 and 2000000 $\mathrm{Da}$, depending on the culture conditions and commercial application of PU (e.g., industrial, medical, and alimentary) (Pradella, 2006). Moreover, digestive enzymes in the human intestine do not degrade PU (Prajapati, Jani, Khanda, 2013). However, it promotes the growth of intestinal Bifidobacterium spp and it can be considered a prebiotic (Silva et al., 2006). It can be used for modified drug release by acting as an enzyme-dependent polymer because it acts as a substrate for this ecosystem.

PU still presents adhesive properties and the capacity to form biodegradable and edible fibers and films (Cheng, Demirci, Catchmark, 2011). The films obtained from this exopolysaccharide are thermally stable, have elastic and antistatic properties, can be used for printing, and are directly compressible under heat and humidity. Additional characteristics include transparency, solubility in water, and insolubility in organic solvents. Furthermore, because of its filmogenic particularities, the addition of a plasticizer is not necessary (Singh, Saini, Kennedy, 2008; Islam, Yeum, Das, 2012; Wu et al., 2013).

To discover a convenient way to explore $\mathrm{pH}$ and enzyme-dependent synergistic properties, the goal of the present study was to develop a novel polymeric material destined for drug release in the distal part of the GIT by associating the polymethacrylate EFS and polysaccharide PU.

\section{MATERIAL AND METHODS}

\section{Material}

Alimentary-grade pullulan (CAS 9057-02-7; Tovani Benzaquem Ingredientes ${ }^{\circledR}$, Brazil), Eudragit ${ }^{\circledR}$ FS 30 D (CAS 26936-24-3; Evonik $^{\circledR}$, Germany), polysorbate 80, glyceryl monostearate, sodium chloride, hydrochloric acid, sodium hydroxide, monobasic potassium phosphate, and distilled water were used. All of the reagents had analytical purity.

\section{Preparation of free films}

The films were produced using a casting process, in which the aqueous dispersion of the synthetic polymer EFS was associated with the polysaccharide PU in varying mass proportions: 100:00, 95:05, 90:10, and 80:20 respectively.

Initially, the polymethacrylate EFS was shaken at $50{ }^{\circ} \mathrm{C}$ for $30 \mathrm{~min}$ with a $5 \%$ emulsion of the sliding glyceryl monostearate and wetting agent polysorbate $80(2 \%)$ according to the methods proposed by Rabito et al. (2012) to obtain a homogeneous dispersion. Concomitantly, PU was dissolved in distilled water, heated at $50{ }^{\circ} \mathrm{C}$, and slowly added to the polymethacrylate dispersion. The final dispersion after total homogeneity was poured into Teflon molds in $10 \mathrm{ml}$ samples and maintained in an oven at $50 \pm 2{ }^{\circ} \mathrm{C}$ for approximately $24 \mathrm{~h}$. After complete solvent evaporation, the films were carefully removed from the molds and stored in desiccators that contained silica gel. For infrared testing, thermal behavior analysis, and mechanical analysis, films of $100 \%$ PU were also prepared. The final polymeric concentration was maintained at a constant $4 \% \mathrm{w} / \mathrm{v}$ for all of the formulations.

The film thickness was determined using a Mitutoyo ${ }^{\circledR}$ micrometer with $0.01 \mathrm{~mm}$ precision. Five different points were measured in three samples of isolated films for each association. Statistical analysis was performed by means of Analysis of Variance using a confidence level of 95\%.

\section{Water vapor transmission (WVT)}

Method "B" (E 96-66) of the American Society for Testing and Materials (ASTM, 1966) was used to verify the films' water vapor permeability. Films with an area of $10 \mathrm{~cm}^{2}$ were fixed in Payne permeability cups (Braive Instruments) that contained $10 \mathrm{ml}$ of distilled water, and the set was weighed at predetermined times $(0,24,48,72$, 96 , and $120 \mathrm{~h}$ ) until obtaining constant rate.

Tests were performed in triplicate, and the cups were stored in desiccators that contained dehydrated silica gel, 
which was replaced at each weighing. From the mass loss, the rate of water vapor transmission was calculated using Equation 1 (Van Den Mooter, Samyn, Kinget, 1994):

$$
\mathrm{WVT}=\mathrm{g} \times 24 / \mathrm{t} \times \mathrm{a} \quad \text { (Equation } 1)
$$

where $g$ is the mass loss $(\mathrm{g}), t$ is the time in hours during which the weights were monitored (h), and $a$ is the film area $\left(\mathrm{m}^{2}\right)$.

\section{Swelling index (Is\%)}

To evaluate the swelling index of the polymer materials, film samples were sliced with surgical scissors at approximately $1 \mathrm{~cm}^{2}$. To remove any residual humidity, the samples were left in an oven at $50^{\circ} \mathrm{C}$ until reaching a constant weight.

Each sample was weighed on an analytical scale to obtain the dry weight and immersed in simulated gastric fluid (SGF; $\mathrm{pH}$ 1.2) or simulated intestinal fluid (SIF; $\mathrm{pH}$ 6.8) prepared according to the $35^{\text {th }}$ edition of the United States Pharmacopeia (USP, 2011), but without the addition of enzyme. At each interval $(10,30,60,90,120,150$, and $180 \mathrm{~min}$ ) (Ghaffari et al., 2007), the films were carefully removed from the immersion media, and the excess liquid was removed with filter paper. The samples were weighed again to determine hydration. The procedure was performed in triplicate.

The films' swelling indices (Is\%) were established according to Equation 2, where $W d$ represents the film's dry mass (g), and Ws represents the film's mass after immersion $(\mathrm{g})$.

$$
\mathrm{Is} \%=(\mathrm{Ws}-\mathrm{Wd}) \times 100 / \mathrm{Wd} \quad(\text { Equation } 2)
$$

\section{Fourier transform infrared spectroscopy (FTIR)}

The infrared absorption spectroscopy assay was performed using the Attenuated Total Reflectance technique with 32 scans at a pressure of 530 pounds per square inch (psi) using an FTIR BOMEM-MB-100 $\left(\right.$ Michelson $\left.^{\circledR}\right)$ spectrophotometer.

\section{Thermogravimetric analysis (TGA)}

The thermal stability of the different compositions of polymeric films was evaluated using thermogravimetric analysis with a Simultaneous Thermal Analyzer STA 409 PC Luxx $\left(\mathrm{Netzsch}^{\circledR}\right)$. Approximately $6 \mathrm{mg}$ samples were previously dehydrated, entrapped in a Pt-Rd crucible, and subjected to an atmosphere with a $30 \mathrm{~mL} / \mathrm{min}$ flow of nitrogen gas and increasing temperature of $22-900{ }^{\circ} \mathrm{C}$ at $10{ }^{\circ} \mathrm{C} / \mathrm{min}$.

\section{Characterization by Scanning electron microscopy}

Morphological characterization was performed using scanning electron microscopy (SEM). The films were analyzed while drying and after swelling for $3 \mathrm{~h}$ in SGF (pH 1.2) and SIF (pH 6.8). After hydration, the pellicles were frozen at $-18{ }^{\circ} \mathrm{C}$ to conserve their structures and then lyophilized at $-55^{\circ} \mathrm{C}$ for $6 \mathrm{~h}$ in a freeze drying Liotop ${ }^{\circledR}$ L101 (Liobras $^{\circledR}$ ). The samples were metallized with gold and surface micrographs were obtained with a Scanning Electron Microscope SS-550 SUPERSCAN $\left(\mathrm{Shimadzu}^{\circledR}\right)$ operated at $10 \mathrm{keV}$.

\section{Mechanical properties}

According to the ASTM D882 method, mechanical analyses were performed with a texturometer TA.XT2 $\left(\right.$ Stable Microsystems ${ }^{\circledR}$ ) equipped with a $5 \mathrm{~kg}$ load cell in an environment with controlled temperature $\left(25 \pm 1{ }^{\circ} \mathrm{C}\right)$ and humidity ( $55 \pm 3 \%)$.

The samples were cut into sizes of $50 \mathrm{~mm} \times 15$ $\mathrm{mm}$ and adjusted to the equipment grips (Fajardo et al., 2012). The parameters were the following: tension of rupture, maximum elongation, and Young's modulus, directly determined by Exponent 6.1.1.0 software (Stable Microsystems $^{\circledR}$ ). Four samples of each association were analyzed, and the averages were calculated.

\section{Statistical analysis}

Analysis of variance for multiple comparisons were used to compare the values obtained with different proportions of EFS and PU. (Villanova, Oréfice, Cunha, 2010; Xiao, Lim, Tong, 2012). Tukey's test was used for posthoc comparisons of the different polymer associations (Bunhak et al., 2007; Rabito et al., 2012). Student's t-test was used in the swelling index to compare the hydration between two fluids. The level of statistical significance was set at $p<0.05$

\section{RESULTS AND DISCUSSION}

\section{Morphological-macroscopic evaluation and film thickness}

Films that had air bubbles, cracks, or deformities were discarded to avoid interference with the analysis. 
TABLE I - Values of mass loss and water vapor transmission $(n=3)$. Means in a column with different superscripts (a - c) are significantly different $(p<0.05$, by Tukey's test)

\begin{tabular}{lcc}
\hline Polymer association & $\begin{array}{c}\text { WVT } \\
\left(\mathbf{g} / \mathbf{m}^{\mathbf{2}} \mathbf{2 4 h}\right)\end{array}$ & $\begin{array}{c}\text { Values of mass loss } \\
(\mathbf{g} / \mathbf{1 2 0 h})\end{array}$ \\
\hline EFS 100:00 PU & $170.69 \pm 20.55^{\mathrm{a}}$ & $0.85 \pm 0.10$ \\
EFS 95:05 PU & $234.65 \pm 23.56^{\mathrm{b}}$ & $1.17 \pm 0.12$ \\
EFS 90:10 PU & $263.19 \pm 18.72^{\mathrm{b}}$ & $1.32 \pm 0.09$ \\
EFS 80:20 PU & $550.67 \pm 11.64^{\mathrm{c}}$ & $2.75 \pm 0.06$ \\
\hline
\end{tabular}

With regard to opacity, transparency reduced as the polysaccharide concentration increased. The mean thickness was $0.11 \pm 0.01 \mathrm{~mm}$, and no significant differences were found among the samples that had different concentrations of synthetic and natural polymers $(p>0.05)$.

\section{Water vapor transmission}

Table I shows that water vapor permeability was proportional to PU concentration $(p<0.05)$. Cavalcanti et al. (2002) and Bunhak et al. (2007) also observed an increase in WVT when working with combinations of polymethacrylate and polysaccharides, like galactomannans and chondroitin sulfate respectively. This is mainly attributable to an increase in the system's hydrophilicity produced by the natural polymer. However, the WVT obtained in the EFS:PU formulations were inferior to those resulting in the cited works, which represents an advantage, since there is a greater prevention of the premature release of drugs in the upper parts of the GIT.

Additionally, Figure 1 shows a linear relationship between the mass loss and time. Akhgari et al. (2006) obtained similar results working with EFS and inulin.

\section{Swelling index}

Figure 2 shows the swelling index obtained after 180 min immersion in SGF and SIF. Statistical analysis was realized for the swelling index obtained in all the tested times of immersion (10, 30, 60, 90, 120, 150 and $180 \mathrm{~min})$, and, after film immersion in SGF, significant differences $(p<0.05)$ occurred in the samples with 100:00 and 90:10 proportions and 100:00 and 80:20 proportions. For the films immersed in SIF, significant differences were found between films with 100:00 and 80:20 proportions and 95:5 and $80: 20$ proportions. Because of the high hydrophilicity of the natural polymer, films with higher concentrations of PU presented higher levels of hydration.

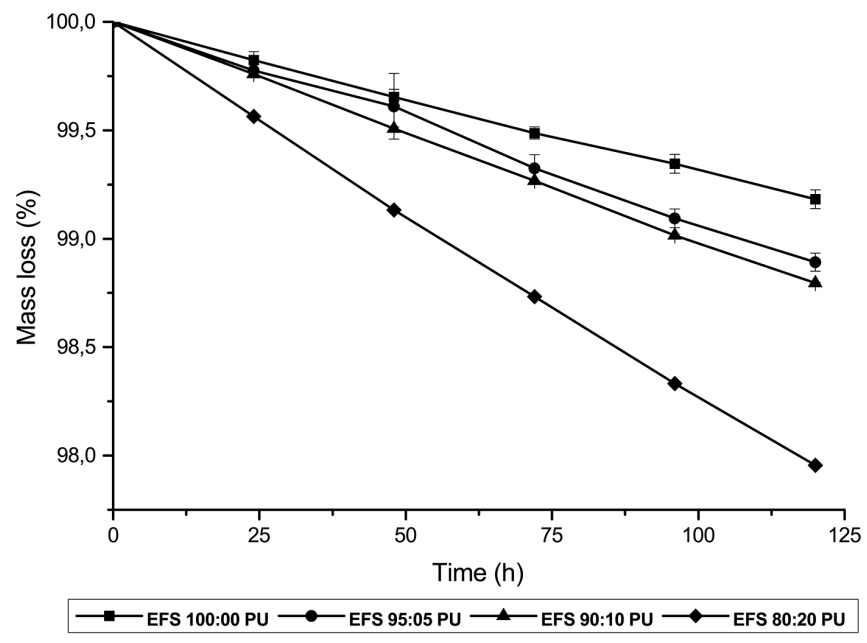

FIGURE 1 - Mass loss for films prepared at different EFS:PU ratios $(n=3)$.

Notable are the results obtained with samples of free films with different associations immersed in $\mathrm{pH}$ $6.8(p<0.05$; i.e., higher Is $\%)$. These findings suggest a predominance of EFS properties because they are $\mathrm{pH}$ dependent and soluble in neutral and slightly alkaline $\mathrm{pH}$. In SIF, this polymer naturally ionized, absorbing large amounts of solvent. Akhgari et al. (2006) previously reported this phenomenon and attributed it to the characteristics of the base synthetic polymer.

Akhgari et al. (2006) working with various combinations of EFS and inulin, obtained Is\% similar to those obtained for the EFS:PU formulations. However, as for the WVT assay, the swelling values in SGF found in the present study were lower, demonstrating a greater resistance to premature drug release in the upper regions of the GIT.

\section{Infrared absorption spectroscopy}

Figure 3 shows that both EFS and PU presented bands in regions similar to the ones reported in the literature. The film that contained only EFS displayed a spectrum with bands at $1161 \mathrm{~cm}^{-1}$ and $1194 \mathrm{~cm}^{-1}$ due to 


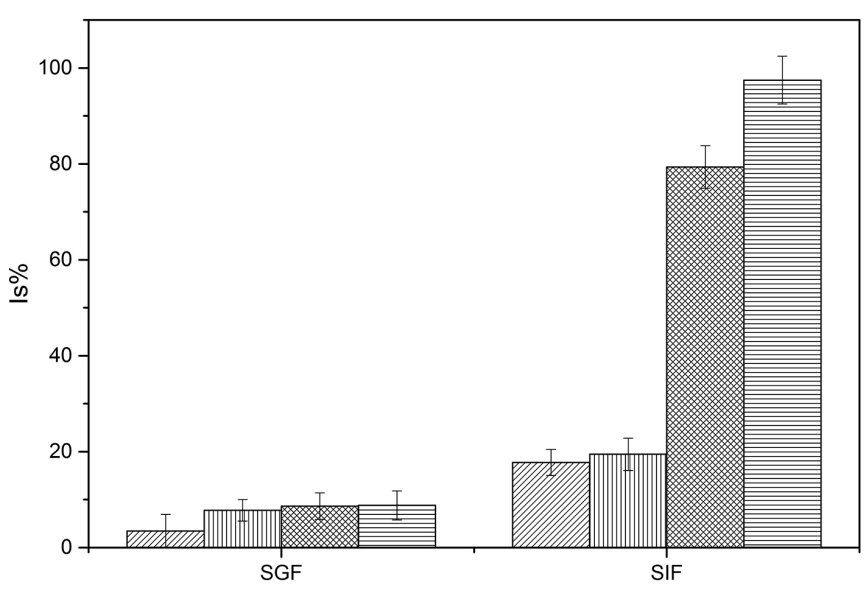

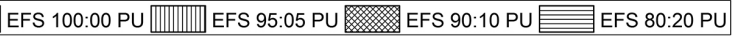

FIGURE 2 - Swelling index of films after $180 \mathrm{~min}$ immersion in $\mathrm{SGF}(\mathrm{pH} 1.2)$ and SIF (pH 6.8) $(\mathrm{n}=3)$.

ester vibrations, a band at $1728 \mathrm{~cm}^{-1}$ that corresponded to vibrations of $\mathrm{C}=\mathrm{O}$ of esterified carboxyl groups, and bands at $2900-3000 \mathrm{~cm}^{-1}, 1387 \mathrm{~cm}^{-1}$, and $1437 \mathrm{~cm}^{-1}$ due to vibrations of $\mathrm{CH}_{\mathrm{x}}$ (Evonik, 2016; Moustafine et al., 2012).

The spectroscopy of PU showed bands at $3331 \mathrm{~cm}^{-1}$ that corresponded to repeated units of hydroxyl groups, $2926 \mathrm{~cm}^{-1}$ due to vibrations of $\mathrm{C}-\mathrm{H}$ linkages, $1641 \mathrm{~cm}^{-1}$ caused by C-O-C linkages, $1358 \mathrm{~cm}^{-1}$ caused by $\mathrm{C}-\mathrm{O}-\mathrm{H}$ linkages, $1148 \mathrm{~cm}^{-1}$ caused by C-O-C linkages, $1012 \mathrm{~cm}^{-1}$ caused by $\mathrm{C}-\mathrm{O}$ linkages, $754 \mathrm{~cm}^{-1}$ that demonstrates the linkages predominant in PU between glucose units $\alpha-(1,4)$ and $\alpha-(1,6), 932 \mathrm{~cm}^{-1}$ related to the presence of glycosidic linkages $\alpha-(1,6)$, and $849 \mathrm{~cm}^{-1}$ due to $\alpha$-configuration (Shingel, 2002; Gniewosz, Duszkiewicz-Reinhard, 2008; Singh, Saini, 2008; Karim et al., 2009; Cheng, Demirci, Catchmark, 2010; Constantin et al., 2011; Bhat et al., 2012; López-Rubio et al., 2012; Sugumaran et al., 2013).

In the compositions 95:5, 90:10, and 80:20, we observed similarities with the spectra of pure EFS that were attributable to the high concentration of this base polymer. For these same associations, in the $1039 \mathrm{~cm}^{-1}$ spectrum region, an increase in the band intensity it was noticed that was proportional to the addition of the polysaccharide, which is likely related to axial symmetric bending of the PU's C-O groups.

Because of the lack of a shift or appearance of new bands, we conclude that only a physical interaction exists between the polymers, without the presence of intermolecular interactions.

\section{Thermogravimetric analysis}

The results of the TGA are presented in Figure 4.

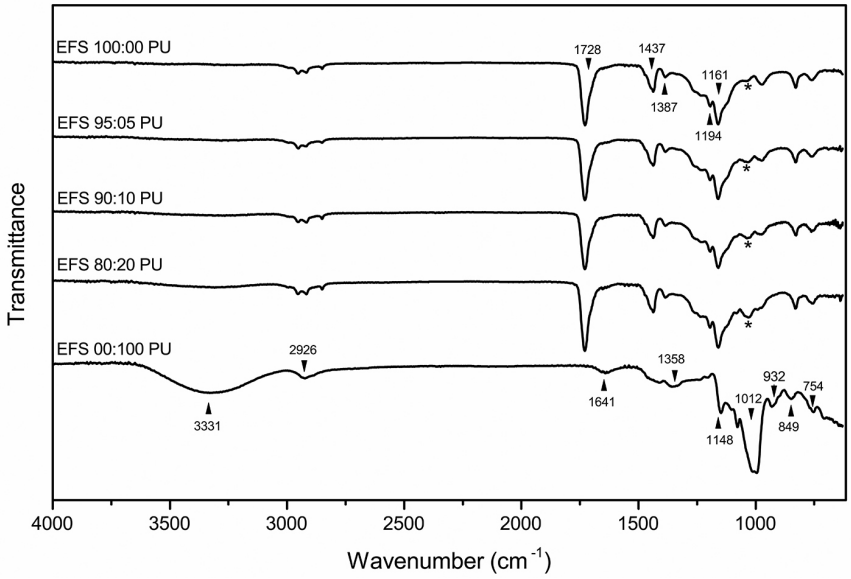

FIGURE 3 - FTIR of polymethacrylate films that contained $0-20 \%$ PU and pure PU.

The degradation temperatures of EFS and PU were close to $400{ }^{\circ} \mathrm{C}$ and $300{ }^{\circ} \mathrm{C}$, respectively. With regard to the associated films, the addition of PU up to $20 \%$ caused the presence of two distinct degradation steps: one related to the polysaccharide and one related to polymethacrylate. This finding suggests a physical interaction between the chains of the synthetic and natural polymers. Additionally, PU presented higher losses of superficial humidity compared with the other samples because of its high hydrophilicity.

From the first derivative of the TGA (DTG; Figure 5), it was noticed that the temperature and speed of maximal mass losses for the natural polymer $\left(319^{\circ} \mathrm{C}\right)$ were lower than the sample that contained only EFS $\left(410^{\circ} \mathrm{C}\right)$. Karim et al. (2009), Constantin et al. (2011), and Teramoto and Shibata (2006) found similar degradation values of PU as the ones in the present study, thus confirming the correct identification of this polysaccharide.

These results suggest that the films based on EFS and PU present suitable thermal stability, when considering that the process of pellicle coating is performed at temperatures of about $40{ }^{\circ} \mathrm{C}$.

\section{Microstructure characterization by Scanning electron microscopy}

As shown in Figure 6, dry films showed minor changes in morphology. When they were immersed in $\mathrm{pH} 1.2$, slight superficial disarrangement due to PU hydrophilicity was observed. At $\mathrm{pH} 6.8$, this disarrangement was more evident, in which the films with 90:10 and 80:20 compositions presented a deeply disordered polymer network. This phenomenon may be related to the $\mathrm{pH}$-dependent properties of the synthetic polymer and structural alterations of the PU network. 


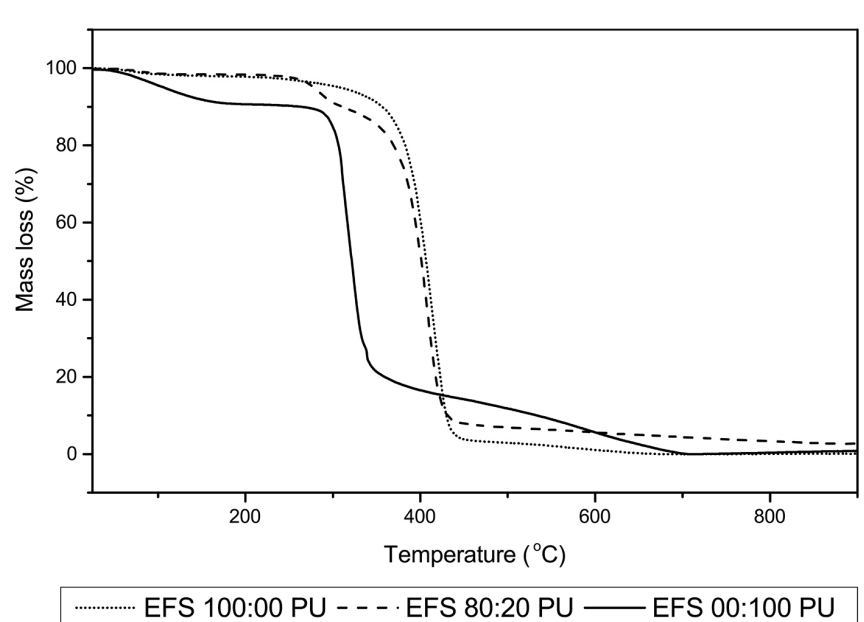

FIGURE 4 - Thermogravimetric analysis of samples of EFS 100:00 PU, EFS 80:20 PU, and EFS 00:100 PU.

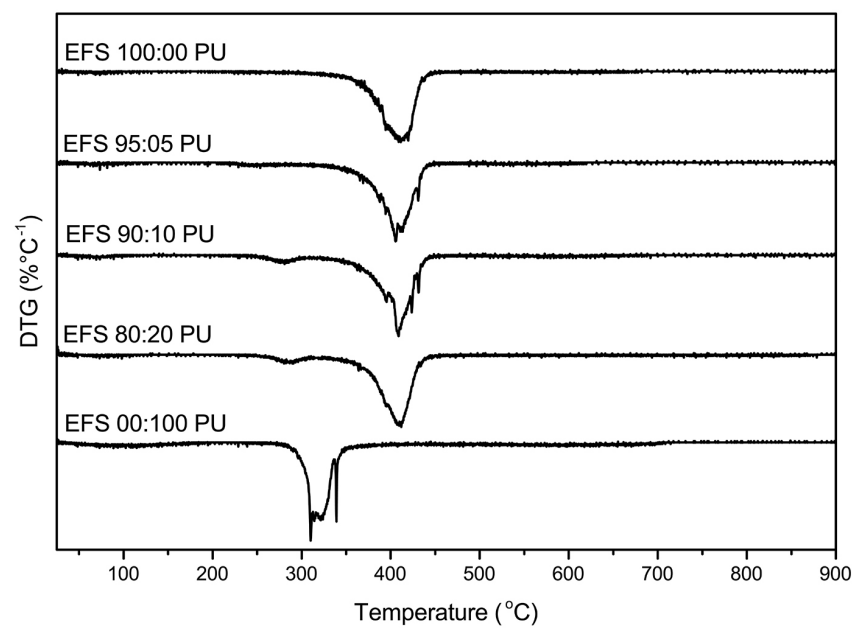

FIGURE 5 - First-derivative TGA of the films with various concentrations.

\section{Mechanical properties}

A film coating's mechanical stability is critical for avoiding breaks and providing adequate physical protection in pharmaceutical forms. The human organism provides several sources of stress for a drug that reaches the GIT, such as shear force that results from the motility of the upper region and hydrostatic pressure exerted by the system against the pellicle after contact with bodily fluids (Karrout et al., 2009a; Karrout et al., 2009b).

Table II shows that the film of pure polymethacrylate and samples that contained both polymers did not differ in terms of the analyzed parameters in the tensile assay $(p>0.05)$. Therefore, the addition of the polysaccharide did not alter the mechanical characteristics of EFS, in which the properties were adequate for coating

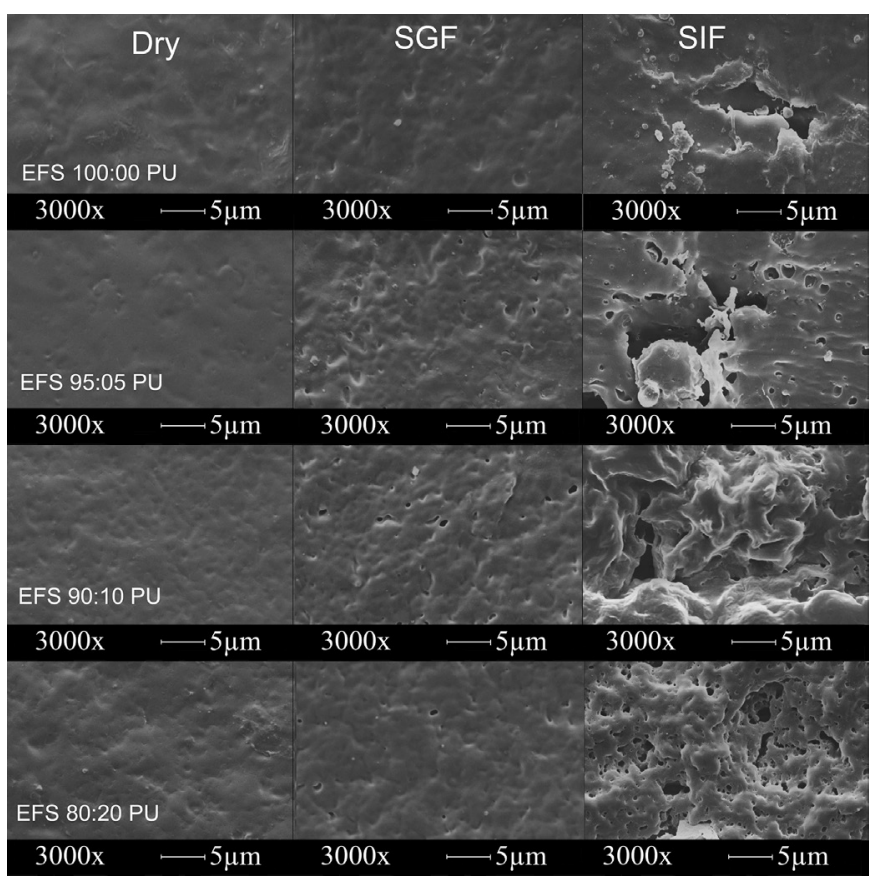

FIGURE 6 - SEM of dry EFS:PU films and after immersion for 180 min at SGF and SIF (3000x magnification).

pharmaceutical forms, since it is a product marketed for this purpose.

Another important result was the reduction of Young's modulus values, characterizing a polymer material with a relative flexibility. Polymers used as pharmaceutical coatings must be elastic and flexible to be adaptable to the deformations and edges associated with pharmaceutical forms without rupturing (Murthy Dwibhashyam, Ratna, 2008).

On the other hand, the film that contained only PU showed superior values for all parameters. Because it has high hydrophilicity, this polymer presents high amounts of intermolecular hydrogen linkages between hydroxyl groups, which can justify the higher thresholds of rupture tension (Tang et al., 2010). Comparisons between different studies are difficult because pellicle preparation and methods influence the tensile test results (Macleod, Fell, Collett, 1997). However, Xiao, Lim and Tong (2012) and Teramoto and Shibata (2006) obtained maximal elongation results for PU that were similar to the present results.

\section{CONCLUSION}

The novel polymer material prepared by incorporating PU with the polymethacrylate EFS presented promising characteristics and properties for application in systems destined for enteric drug release. It is observed an adequate resistance to GIT fluids; and 
TABLE II - Mechanical properties of EFS:PU films $(n=4)$. Means in a column with different superscripts $(a-b)$ are significantly different $(p<0.05$, by Tukey's test)

\begin{tabular}{lccc}
\hline Sample & Rupture tension (KPa) & Maximal elongation (\%) & $\begin{array}{c}\text { Young's modulus } \\
(\text { KPa) }\end{array}$ \\
\hline EFS 100:00 PU & $18.31 \pm 2.66^{\mathrm{a}}$ & $0.61 \pm 0.13^{\mathrm{a}}$ & $25.17 \pm 2.39^{\mathrm{a}}$ \\
EFS 95:05 PU & $17.10 \pm 4.17^{\mathrm{a}}$ & $0.71 \pm 0.19^{\mathrm{a}}$ & $24.50 \pm 5.12^{\mathrm{a}}$ \\
EFS 90:10 PU & $19.80 \pm 7.58^{\mathrm{a}}$ & $0.68 \pm 0.41^{\mathrm{a}}$ & $24.25 \pm 1.60^{\mathrm{a}}$ \\
EFS 80:20 PU & $15.31 \pm 1.48^{\mathrm{a}}$ & $1.17 \pm 0.58^{\mathrm{a}}$ & $22.78 \pm 5.19^{\mathrm{a}}$ \\
EFS 00:100 PU & $71.41 \pm 5.96^{\mathrm{b}}$ & $2.26 \pm 0.82^{\mathrm{b}}$ & $42.35 \pm 5.74^{\mathrm{b}}$ \\
\hline
\end{tabular}

mechanical properties and thermal stability compatible with processes required for film coating. The individual properties of each polymer in the associations were preserved, causing only physical interactions between the content of the formulations. The preserved properties open up opportunities to exploit the synergism between the $\mathrm{pH}$ sensitivity properties of polymethacrylate and enzyme-dependent properties of PU. In addition, when compared with some other polymeric films developed with the purpose of enteric release (which use various methacrylates:polysaccharides formulations), proved to be more resistant to premature release of drugs in the upper parts of the GIT.

These findings suggest that the material obtained in the present study has properties that may be applied as coatings for colon-specificity. However, complementary in vivo and in vitro assays are needed to confirm this indication.

\section{ACKNOWLEDGEMENTS}

The authors thank CAPES (Brazil) for providing a master student fellowship.

\section{REFERENCES}

Akhgari A, Farahmand F, Afrasiabi Garekani H, Sadeghi F, Vandamme TF. Permeability and swelling studies on free films containing inulin in combination with different polymethacrylates aimed for colonic drug delivery. Eur J Pharm Sci. 2006;28(4):307-14.

American Society for Testing and Materials. ASTM. Standard methods of test for water vapor transmission of materials in sheet form - E 96-66. Philadelphia; 1966.
Basit AW, McConnell EL. Drug delivery to the colon. In: Wilson CG, Crowley PJ, editors. Controlled release in oral drug delivery: advances in delivery science and technology. Switzerland: Springer; 2011. p. 385-99.

Bhat V, Shivakumar HR, Rai KS, Sanjeev G. Effect of electron beam irradiation on physico-chemical properties of pullulan. J Radioanal Nucl Chem. 2012;293(1):431-5.

Bunhak ÉJ, Mendes ES, Pereira NC, Cavalcanti OA. Influência do sulfato de condroitina na formação de filmes isolados de polimetacrilato: avaliação do índice de intumescimento e permeabilidade ao vapor d'água. Quim Nova. 2007;30:312-7.

Cavalcanti OA, Mooter GVd, Caramico-Soares I, Kinget R. Polysaccharides as excipients for colon-specific coatings. permeability and swelling properties of casted films. Drug Dev Ind Pharm. 2002;28(2):157-64.

Cheng KC, Demirci A, Catchmark JM. Effects of plastic composite support and $\mathrm{pH}$ profiles on pullulan production in a biofilm reactor. Appl Microbiol Biotechnol. 2010;86(3):853-61.

Cheng KC, Demirci A, Catchmark JM. Pullulan: biosynthesis, production, and applications. Appl Microbiol Biotechnol. 2011;92(1):29-44.

Constantin M, Mihalcea I, Oanea I, Harabagiu V, Fundueanu G. Studies on graft copolymerization of 3-acrylamidopropyl trimethylammonium chloride on pullulan. Carbohydr Polym. 2011;84(3):926-32.

Dulin W. Oral targeted drug delivery systems: enteric coating. In: Wen H, Park K, editors. Oral controlled release formulation design and drug delivery. New Jersey: John Wiley \& Sons; 2010. p. 205-23. 
Evonik. Evonik Industries. Eudragit ${ }^{\circledR}$ FS 30 D - Technical information: specification and test methods. [cited $2016 \mathrm{Aug}$ 2]. Avaiable from: http://eudragit.evonik.com/sites/lists/HN/ ProductSpecifications/evonik-specification-eudragit-fs-30-d. pdf.

Fajardo AR, Lopes LC, Rubira AF, Muniz EC. Development and application of chitosan/poly(vinyl alcohol) films for removal and recovery of $\mathrm{Pb}$ (II). Chem Eng J. 2012;183:253-60.

Freire AC, Podczeck F, Sousa J, Veiga F. Liberação específica de fármacos para administração no cólon por via oral. I - O cólon como local de liberação de fármacos. Rev Bras Cienc Farm. 2006;42(3):319-35.

Ghaffari A, Navaee K, Oskoui M, Bayati K, Rafiee-Tehrani M. Preparation and characterization of free mixed-film of pectin/ chitosan/Eudragit ${ }^{\circledR}$ RS intended for sigmoidal drug delivery. Eur J Pharm Biopharm. 2007;67(1):175-86.

Gniewosz M, Duszkiewicz-Reinhard W. Comparative studies on pullulan synthesis, melanin synthesis and morphology of white mutant Aureobasidium pullulans B-1 and parent strain A.p.-3. Carbohydr Polym. 2008;72(3):431-8.

Ibekwe VC, Fadda HM, Parsons GE, Basit AW. A comparative in vitro assessment of the drug release performance of $\mathrm{pH}$ responsive polymers for ileo-colonic delivery. Int J Pharm. 2006;308(1-2):52-60.

Ibekwe VC, Khela MK, Evans DF, Basit AW. A new concept in colonic drug targeting: a combined $\mathrm{pH}$-responsive and bacterially-triggered drug delivery technology. Aliment Pharmacol Ther. 2008;28(7):911-6.

Introzzi L, Fuentes-Alventosa JM, Cozzolino CA, Trabattoni S, Tavazzi S, Bianchi CL, et al. "Wetting Enhancer" Pullulan coating for antifog packaging applications. ACS Appl Mater Interfaces. 2012;127(1):118-21.

Islam MS, Yeum JH, Das AK. Effect of pullulan/poly(vinyl alcohol) blend system on the montmorillonite structure with property characterization of electrospun pullulan/poly(vinyl alcohol)/montmorillonite nanofibers. J Colloid Interf Sci. 2012;368(1):273-81.

Karim MR, Lee HW, Kim R, Ji BC, Cho JW, Son TW, et al. Preparation and characterization of electrospun pullulan/ montmorillonite nanofiber mats in aqueous solution. Carbohydr Polym. 2009;78(2):336-42.
Karrout Y, Neut C, Wils D, Siepmann F, Deremaux L, Desreumaux P, et al. Characterization of ethylcellulose: starchbased film coatings for colon targeting. Drug Dev Ind Pharm. 2009a;35(10):1190-200.

Karrout Y, Neut C, Wils D, Siepmann F, Deremaux L, Desreumaux P, et al. Novel polymeric film coatings for colon targeting: How to adjust desired membrane properties. Int $\mathrm{J}$ Pharm. 2009b;371(1-2):64-70.

López-Rubio A, Sanchez E, Wilkanowicz S, Sanz Y, Lagaron JM. Electrospinning as a useful technique for the encapsulation of living bifidobacteria in food hydrocolloids. Food Hydrocoll. 2012;28(1):159-67.

Macleod GS, Fell JT, Collett JH. Studies on the physical properties of mixed pectin/ethylcellulose films intended for colonic drug delivery. Int J Pharm. 1997;157(1):53-60.

McConnell EL, Short MD, Basit AW. An in vivo comparison of intestinal $\mathrm{pH}$ and bacteria as physiological trigger mechanisms for colonic targeting in man. J Control Release. 2008;130(2):15460 .

Moustafine RI, Bodrov AV, Kemenova VA, Rombaut P, Van den Mooter G. Drug release modification by interpolymer interaction between countercharged types of Eudragit ${ }^{\mathbb{R}}$ RL 30D and FS 30D in double-layer films. Int J Pharm. 2012;439(1-2):17-21.

Murthy Dwibhashyam VSN, Ratna JV. Key formulation variables in tableting of coated pellets. Indian J Pharm Sci. 2008;70(5):555-64.

Nadler Milabuer M, Kam Y, Rubinstein A. Orally administered drug delivery systems to the colon. In: Wen H, Park K, editors. Oral controlled release formulation design and drug delivery. New Jersey: John Wiley \& Sons; 2010. p. 225-43.

Pinto JF. Site-specific drug delivery systems within the gastrointestinal tract: from the mouth to the colon. Int J Pharm. 2010;395(1-2):44-52.

Pradella JGC. Biopolímeros e intermediários químicos. Relatório Técnico No 84 396-205. São Paulo: Centro de Tecnologia de Processos e Produtos, Laboratório de Biotecnologia Industrial - LBI/CTPP; 2006. 119 p.

Prajapati VD, Jani GK, Khanda SM. Pullulan: an exopolysaccharide and its various applications. Carbohydr Polym. 2013;95(1):540-9. 
Rabito MF, Reis AV, Freitas Ados R, Tambourgi EB, Cavalcanti OA. A pH/enzyme-responsive polymer film consisting of Eudragit FS $30 \mathrm{D}$ and arabinoxylane as a potential material formulation for colon-specific drug delivery system. Pharm Dev Technol. 2012;17(4):429-36.

Shingel KI. Determination of structural peculiarities of dexran, pullulan and $\gamma$-irradiated pullulan by Fourier-transform IR spectroscopy. Carbohydr Res. 2002;337(16):1445-51.

Shukla RK, Tiwari A. Carbohydrate polymers: Applications and recent advances in delivering drugs to the colon. Carbohydr Polym. 2012;88(2):399-416.

Silva DA, Feitosa JPA, Maciel JS, Paula HCB, de Paula RCM. Characterization of crosslinked cashew gum derivatives. Carbohydr Polym. 2006;66(1):16-26.

Singh RS, Saini GK, Kennedy JF. Pullulan: Microbial sources, production and applications. Carbohydr Polym. 2008;73(4):51531.

Singh RS, Saini GK. Pullulan-hyperproducing color variant strain of Aureobasidium pullulans FB-1 newly isolated from phylloplane of Ficus sp. Bioresour Technol. 2008;99(9):3896-9.

Sugumaran KR, Gowthami E, Swathi B, Elakkiya S, Srivastava SN, Ravikumar R, et al. Production of pullulan by Aureobasidium pullulans from Asian palm kernel: A novel substrate. Carbohydr Polym. 2013;92(1):697-703.

Tang M, Hou J, Lei L, Liu X, Guo S, Wang Z, et al. Preparation, characterization and properties of partially hydrolyzed ethylene vinyl acetate copolymer films for controlled drug release. Int $\mathrm{J}$ Pharm. 2010;400(1-2):66-73.
Teramoto N, Shibata M. Synthesis and properties of pullulan acetate. Thermal properties, biodegradability, and a semiclear gel formation in organic solvents. Carbohydr Polym. 2006;63(4):476-81.

United States Pharmacopoeia USP. 35 ed. Rockville: The United States Pharmacopeial Convention; 2011.

Van den Mooter G, Samyn C, Kinget R. The relation between swelling properties and enzymatic degradation of azo polymers designed for colon-specific drug delivery. Pharm Res. 1994;11(12):1737-41.

Villanova JCO, Oréfice RL, Cunha AS. Aplicações farmacêuticas de polímeros. Polímeros. 2010;20:51-64

Wasnik S, Parmar P. The design of colon-specific drug delivery system and different approaches to treat colon disease. Int $\mathrm{J}$ Pharm Sci Rev Res. 2011;6(2):167-77.

Wen H, Park K. Introduction and overview of oral controlled release formulation design. Oral controlled release formulation design and drug delivery. New Jersey: John Wiley \& Sons; 2010. p. 1-19.

Wu J, Zhong F, Li Y, Shoemaker CF, Xia W. Preparation and characterization of pullulan-chitosan and pullulancarboxymethyl chitosan blended films. Food Hydrocoll. 2013;30(1):82-91.

Xiao Q, Lim L-T, Tong Q. Properties of pullulan-based blend films as affected by alginate content and relative humidity. Carbohydr Polym. 2012;87(1):227-34.

Received for publication on $30^{\text {th }}$ September 2016 Accepted for publication on $17^{\text {th }}$ February 2017 